\title{
The many merits of monoclonals
}

\section{Only a decade after the technique for producing monoclonal antibodies sprung serendipitously from an academic line of research, biotechnology companies are thriving on their manufacture.}

IN his Nobel prize lecture (EMBO J. 4, $1083 ; 1985)$, Cesar Milstein describes how his interest in the mechanism by which the immune system is able to generate around $10^{6}-10^{9}$ different antibodies from a very much smaller number of genes had reached a stage in the early 1970 s at which he was convinced that much diversity was generated by frequent mutations in the antibody-producing cells. Such mutations should occur at a detectable rate in cells cultured in the laboratory. But the ordinary antibody-producing cells, B lymphocytes, cannot be cultured, so the obvious trick was to turn to the equivalent tumour cells, from myelomas. The problem then became one of finding a myeloma cell that produced a suitable antibody. Several difficulties led to a decision to fuse myeloma cells with B lymphocytes that were producing suitable antibodies, in the hope of obtaining hybrid cells that both grew well and produced antibody. The approach worked and Milstein is still using it to unravel the details of antibody production, as described in the article on page 412 of this issue. In the meantime, the technique, which was described in a paper published 10 years ago this week (Köhler, G. \& Milstein, C. Nature 256, 495; 1975), has led to Nobel prizes for the authors and a multi-million pound industry.

Because a monoclonal antibody, the product of the technique, is produced from clones of identical hybrid cells (hybridomas), not only can it be made in unlimited quantities but it is also completely specific. Conventionally, antibodies have been produced in limited quantities by injecting an antigen into an experimental animal and later collecting its serum. Since most antigens carry various antigenic determinants, the serum will contain a mixture of antibodies, each one being produced by a different clone of B lymphocytes. A hybridoma perpetuates the production of the single antibody produced by any one clone.

For their initial demonstration of the hybridoma technique, Köhler and Milstein happened to make antibodies against sheep red blood cells, not the most useful of reagents. But, as they wrote, "It is possible to hybridize antibody-producing cells from different origins. Such cells can be grown in vitro in massive cultures to provide specific antibody. Such cultures could be valuable for medical and industrial use."Much to its embarrassment ever since, the National Research and De- velopment Corporation, which until recently (see page 382 ) had prime responsibility for fostering UK research discoveries with an industrial potential, failed to be impressed by the commercial future of monoclonal antibodies. But Milstein was in no doubt. He therefore largely shelved his work on antibody diversity to produce a variety of valuable monoclonal antibodies, including those which are now used for all UK blood typing.

As word and the technique spread among laboratories a cottage industry began. Mostly this consisted of laboratories producing monoclonal antibodies of use for their particular project. Invariably a few other groups working in the same area could make use of the antibodies and would be provided with them on request, although occasionally with some delay or with strings attached. A few monoclonal antibodies, however, were so widely in demand that the burden on the donor became intolerable. Thus, in part, began the commercialization of monoclonals.

At the same time, others were thinking on a grander commercial scale and foresaw large and expanding markets. It was easy to identify the areas in which monoclonal antibodies would have immediate uses on the scale that warranted investment. More of a problem was how to produce them in large quantities and with high purity. Two companies have made the running. One is the UK company Celltech, which had the advantage of access to Milstein's hybridomas and expertise. The other is Damon Biotech, the US company that last week announced its involvement in a consortium that is to build a $£ 30$ million plant in Scotland to produce monoclonal antibodies - most of the finance coming from European venture capital and UK taxpayers one way or another. Celltech and Damon will produce something like 3 kilograms of monoclonal antibodies between them this year out of a worldwide total estimated to be between 10 and 15 kilograms.

Monoclonals are sold for purposes that fall into four main categories - diagnosis, immunopurification, imaging and therapy - of which only the first two constitute an established market. The diagnostic tests that use the antibodies fall into two categories. First are the assays, particularly for hormones, that already rely on antibodies but for which monoclonals have provided increased sensitivity; one benefit is the earlier diagnosis of pregnancy or ovula- tion. Second are tests, particularly for pathogens, that have traditionally relied on several days of culturing but can now be performed in several hours with a monoclonal antibody.

For immunopurification, monoclonal antibodies offer the advantage of being able to separate one substance from a mixture of very similar molecules, not to mention the large background of unrelated substances. For example, it is only because of the availability of large quantities of monoclonal antibodies to individual interferons that several of these molecules have been purified in sufficient quantities for clinical trials.

Therapy and imaging (that is, the use of an isotopically labelled antibody to provide an image of an organ by a noninvasive means) are seen as the immediate goal for expanding companies. Already about 60 applications for such uses have been lodged with the US regulatory bodies and the bets are that at least one will be approved this year, perhaps for an antibody that inactivates the $\mathrm{T}$ lymphocytes responsible for the rejection of organ transplants. Another therapeutic use that has already been put to the clinical test is the removal of tumour cells from bone marrow. Further down the line is the possible use of monoclonal antibodies directed against markers on the surface of solid tumours to kill the tumours. Here the idea is either to link the antibody to a toxic drug that would be delivered specifically to the tumour or to use the antibody alone to cause the tumour to regress.

Beyond that are many thoughts, some merely fanciful, of second-generation monoclonal antibodies, most of which will be the result of engineering antibody genes. There is also a quest to produce human, rather than mouse, antibodies because, during repeated therapeutic use, mouse monoclonals may stimulate the human immune system against them.

Already the short history of monoclonal antibodies serves as a classic case with which to illustrate the economic wisdom of maintaining healthy financial support for curiosity-driven research. So widespread now is the use of monoclonal antibodies in molecular and cell biology that it seems almost inevitable that they will contribute to some of the next technologies that will spring serendipitously from research of as little apparent 'relevance' as that long pursued by Cesar Milstein.

Peter Newmark 